\title{
The Effect of Repair Welding Number on Microstructure of Hastelloy X Fabricated via TIG Process
}

\author{
Mohammad Reza Abedi ${ }^{1}$, Hamed Sabet ${ }^{1,}$, , Hossein Razavi ${ }^{2}$ \\ ${ }^{1}$ Department of Materials Engineering, Karaj Branch, Islamic Azad University, Karaj, Iran \\ ${ }^{2}$ Department of Metallurgy and Materials Engineering, Iran University of Science and Technology (IUST), Tehran, Iran \\ Email address: \\ h-sabet@kiau.ac.ir (H. Sabet) \\ ${ }^{*}$ Corresponding author
}

To cite this article:

Mohammad Reza Abedi, Hamed Sabet, Hossein Razavi. The Effect of Repair Welding Number on Microstructure of Hastelloy X Fabricated via TIG Process. International Journal of Materials Science and Applications. Vol. 5, No. 2, 2016, pp. 43-48.

doi: 10.11648/j.ijmsa.20160502.12

Received: November 22, 2015; Accepted: December 5, 2015; Published: March 21, 2016

\begin{abstract}
The effect of repair welding number on microstructure of the hastelloy X fabricated via TIG process was investigated. The SEM, EDS and OM were used to determine mechanical properties and the microstructure of HAZ zone, respectively. Results showed that the grain size of base metal determined by OM and SEM was $64.11 \mu \mathrm{m}$ with $\mathrm{M}_{6} \mathrm{C}$ and $\mathrm{M}_{23} \mathrm{C}_{6}$ carbides $(6.16,18.71 \mu \mathrm{m}$ respectively). Also, using welding for three times caused increase of grain size $(15 \%, 22 \%, 26 \%$ respectively) and the heat input made some carbides dissolve. The grain growth through HAZ zone venially affected the strength of alloy. The results of tensile test demonstrated that UTS increased by repair welding, 1\%, 2\% and 3\% respectively. As the UTS of base metal was $727 \mathrm{MPa}$, the fracture phenomenon occurred. Furthermore, repair welding of mentioned alloy did not exceed more than three times.
\end{abstract}

Keywords: GTAW, Hastelloy X, Microstructure, Carbides

\section{Introduction}

Super alloys are widely used in many industrial fields because of its superior properties such as high strength at high temperatures and high oxidation and hot corrosion resistant. Nickel-based super alloys are widely used as high temperature turbine components. Hastalloy $\mathrm{X}$ alloy is used in high temperature applications that are often under high stresses and cyclic loadings conditions. Hastelloy X super alloy is a nickel based alloy strengthened by solid solution [1].

Its alloying elements are chosen in a way increasing the mechanical properties and improving high temperature corrosion, creep resistance, fracture toughness, and structural stability $[2,3]$.

Nickel base super alloys like Hastelloy X can be welded by all fusion welding processes such as GTAW, GMAW, SMAW, SAW, PAW, EBW and RSW. GTAW is widely used for all parts of material especially for thin parts. The GTAW welding parameters influence the quality, productivity and cost of welding joint. The perfect arc can be achieved if all the welding parameters are conformed. The matrix of this super alloy is austenite.

In fusion welding process, depending on the heating and cooling conditions and heat input, microstructure, chemical composition and mechanical properties of heat-affected HAZ drastically differ from the unaffected base metal (BM). During the welding, in heat-affected zone of Hastelloy $\mathrm{X}$, the amounts of $\mathrm{M}_{6} \mathrm{C}$ and $\mathrm{M}_{23} \mathrm{C}_{6}$ carbides change.

The $\gamma^{\prime}$ precipitations are not observed in the microstructure due to high amounts of $\mathrm{Al}$ and Ti. Since the amount of the elements such as $\mathrm{Al}, \mathrm{Hf}, \mathrm{Ta}$, and Ti is very low in Hastelloy $\mathrm{X}$, formation of $\gamma^{\prime}$ does not occur in structure of this alloy. Microstructure composition of the alloy contains an austenite matrix and $\mathrm{M}_{6} \mathrm{C}$ and $\mathrm{M}_{23} \mathrm{C}_{6}$ carbides enriched in $\mathrm{Mo}$ and $\mathrm{Cr}$ elements, respectively [3].

Most previous investigations focus on the one-time welding of Hastelloy X. Stolloff [5] observed that precipitation of fine carbide particles in the matrix of Hastelloy $\mathrm{X}$ increased the strength of the alloy. Effects of minor elements were considered by Richards and Chaturvedi [6]. Wang et al [7] focused on the influences of parameters of tungsten inert gas arc welding on the morphology, microstructure, tensile property and fracture of 
welded joints of Ni-base super alloy. Results show that the increase of welding current and the decrease of welding speed bring about the large amount of heating put in welding pool and the enlargement of width and deepness of the welding pool. The heat input increases with the decrease of welding speed and the increase of welding current [7]. Zhang Lee et al [9] Worked on the hardness and strength in the welding zone of the Hastelloy $\mathrm{X}$ is due to $\mathrm{M}_{6} \mathrm{C}$ carbides and their distribution. Zhang et al. [8] suggested about analysis on the micro fissuring behavior in the heat- affected zone in Nickel-base super alloy and observed that during the $\mathrm{CO}_{2}$ laser welding, Hastelloy $\mathrm{X}$ dissimilar with Mar-M247 alloy was formed through the epitaxial growth process in the interface of weld metal and base metal in the Hastelloy X [8]. According to the high price of super alloys and also its need to frequent repairing, there is no evidence research about the number of repair welding on these super alloys. This study investigated effect of the welding parameters such as number of repair on morphology and mechanical properties of the hastelloy $\mathrm{X}$ fabricated via TIG process.

\section{Experimental Procedure}

Firstly, the samples were cut to reach the required dimensions, $350 \times 150 \times 2 \mathrm{~mm}$, according to ISO 15614-1. Standard square butt joints were used for the welding of samples. Specially designed fixture was used for welding

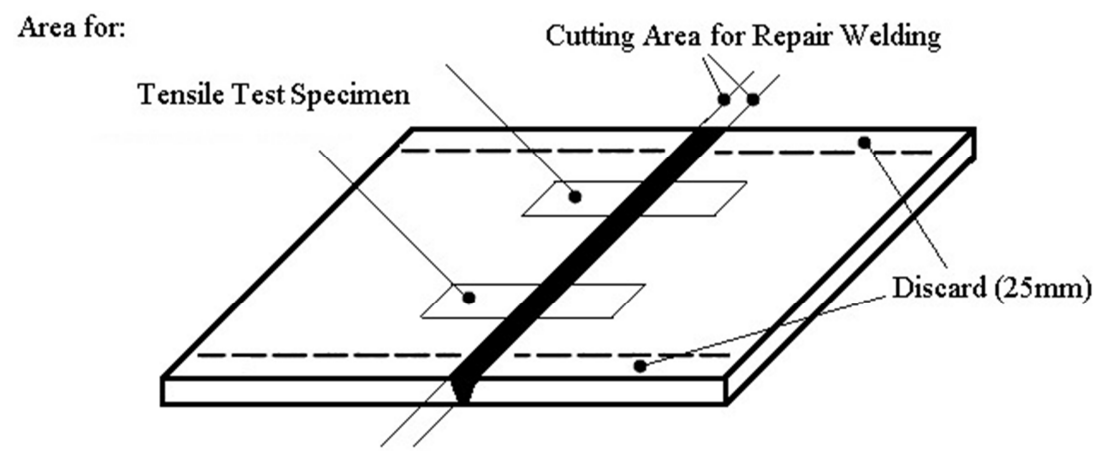

Figure 1. Schematic image of specimens.

Finally, OM and SEM were used to determine microstructure and grain size.

Table 3. Chemical composition of wire welding ERNiCrMo-3 (Wt\%) [7].

\begin{tabular}{|c|c|c|c|c|c|c|c|c|c|c|c|c|c|}
\hline Element & $\mathrm{Ni}$ & $\mathrm{Cr}$ & $\mathrm{Fe}$ & Mo & $\mathrm{Nb} / \mathrm{Ta}$ & $\mathbf{T i}$ & C & Mn & $\mathbf{S i}$ & Al & $\mathbf{C u}$ & $\mathbf{S}$ & $\mathbf{P}$ \\
\hline $\mathrm{Wt} \%$ & ${ }^{\mathrm{a}} 58$ & $20-23$ & 5 & $8-10$ & $3-4$ & 0.4 & 0.10 & 0.5 & 0.5 & 0.4 & 0.5 & 0.015 & 0.02 \\
\hline
\end{tabular}

Table 4. Mechanical properties of ERNiCrMo-3 [7].

\begin{tabular}{lll}
\hline Ultimate Tensile Strength(MPa) & Yield Strength at 0.2\% Offset (MPa) & Elongation (\%) \\
\hline 786 & 455 & 35 \\
\hline
\end{tabular}

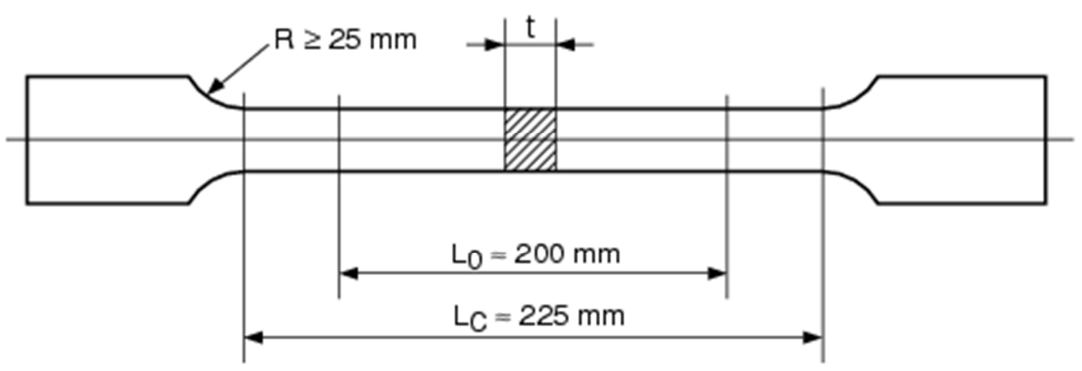

Figure 2. Schematic image of tensile test. 
After welding of all specimens, the samples were cut perpendicular using a cut-off machine. The microstructure was revealed using an etchant. The microstructures of samples were studied by optical microscope equipped with image analysis software (MEIJI Techno), scanning electron microscope (SEM- Seron tech) using backscattered (BSE) and energy dispersive spectrometry (EDS) with $16.0 \mathrm{kV}$ accelerated voltage. Tensile test was done according to the EN 895 that two samples are provided for each of the three specimens as shown in figure 2 .

\section{Results and Discussion}

\subsection{Microstructure and SEM Analysis}

Figure 4 indicates OM micrographs of Hastelloy X. As observed, the microstructure of this alloy included continuous phase $\gamma$ (austenite) in the mixture. Grain size of base metal measured via image analysis software was 64.11, 6.16 and $18.71 \mu \mathrm{m}$, for $\mathrm{M}_{6} \mathrm{C}$ and for $\mathrm{M}_{23} \mathrm{C}_{6}$ inclusive samples, respectively. Increase of Grain size was 15, 22 and 26\% for one-time, two-time and three- time welding, respectively. Moreover, decrease of $\mathrm{M}_{6} \mathrm{C}$ carbides was 34,49 and $50 \%$, respectively. Also, increase of $\mathrm{M}_{23} \mathrm{C}_{6}$ carbides was 32, 39 and $50 \%$ for one- time, two -time and three time welding. Fig 6 and 7 provide EDS spectroscopy results performed as a elemental analysis. As seen, $\mathrm{M}_{6} \mathrm{C}$ and $\mathrm{M}_{23} \mathrm{C}_{6}$ carbides were significantly observed in matrix and boundaries, respectively. A significant difference was observed between weight percent of nickel and other elements. The microstructure of this alloy included fine particles and carbides distributed in the context, as shown in Fig 4 and 5.

Table 5. Grain sizes and carbides sizes in HAZ.

\begin{tabular}{|c|c|c|c|c|c|c|}
\hline Sample & Grain sizes $(\mu \mathrm{m})$ & Percentage (increasing) & $M_{6} C(\mu \mathrm{m})$ & Percentage (decreasing) & $\mathrm{M}_{23} \mathrm{C}_{6}$ & Percentage (increasing) \\
\hline Base metal & 64.11 & - & 6.16 & - & 18.71 & - \\
\hline one-time Welding & 73.94 & $15 \%$ & 4.015 & $34 \%$ & 24.70 & $32 \%$ \\
\hline two-time Welding & 78.648 & $22 \%$ & 3.099 & $49 \%$ & 26.15 & $39 \%$ \\
\hline three-time Welding & 81.335 & $26 \%$ & 3.08 & $50 \%$ & 28.24 & $50 \%$ \\
\hline
\end{tabular}

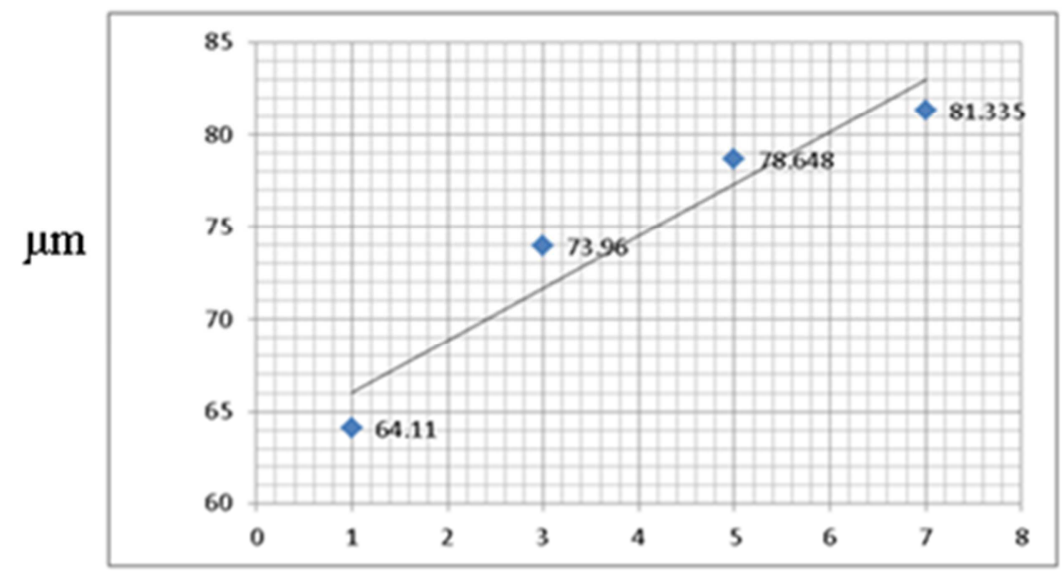

Grain sizes

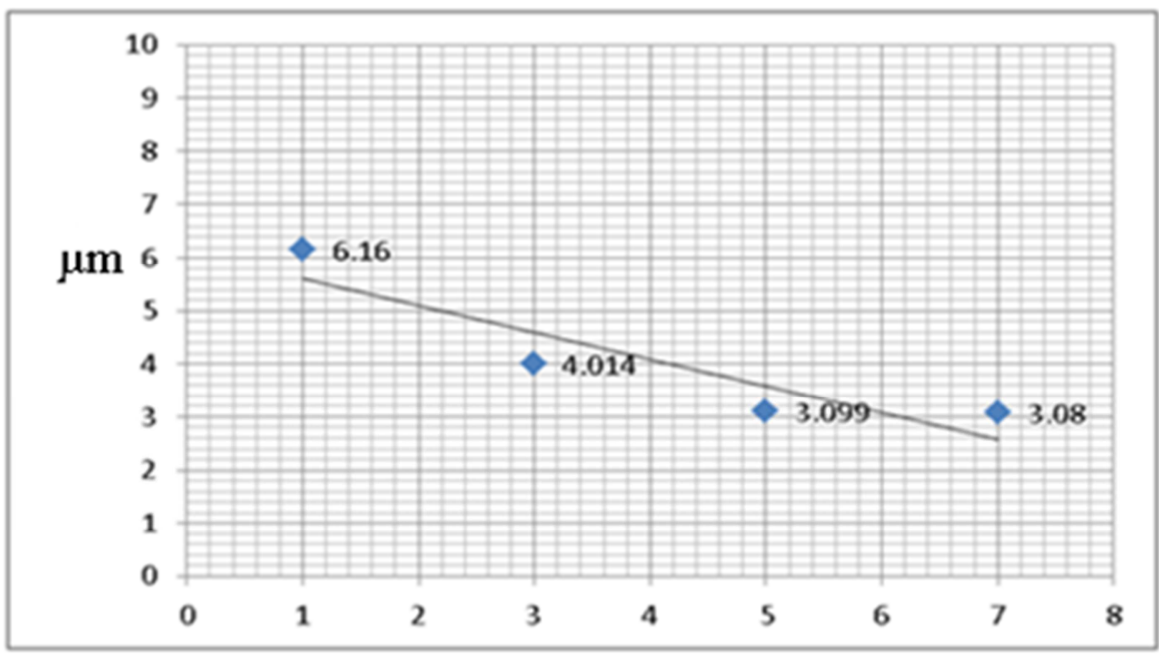




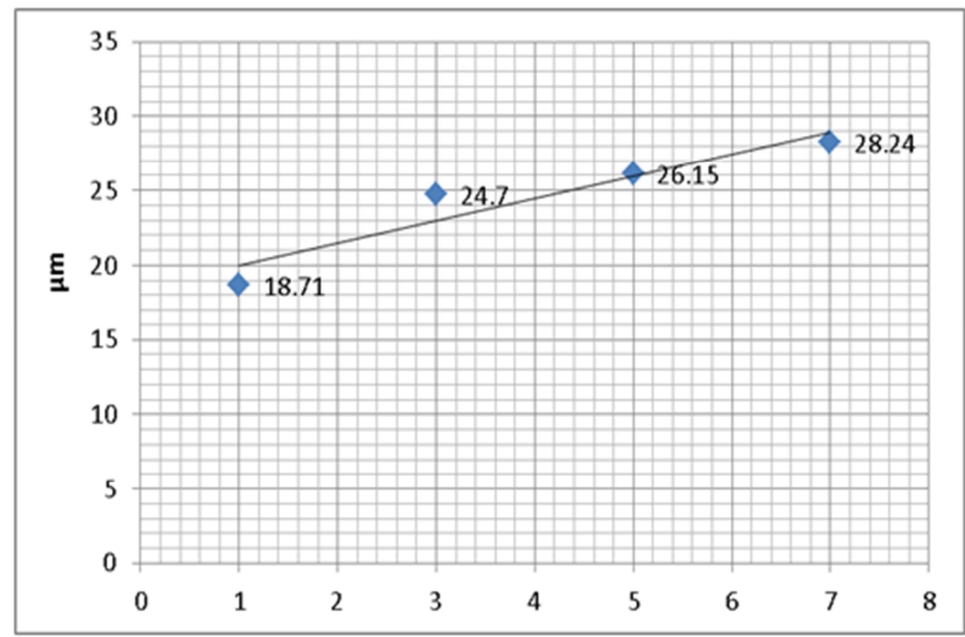

$\mathrm{M}_{23} \mathrm{C}_{6}$

Figure 3. Sizes of grain and carbides.

Heat input during the welding caused grain growth and dissolution of carbides.

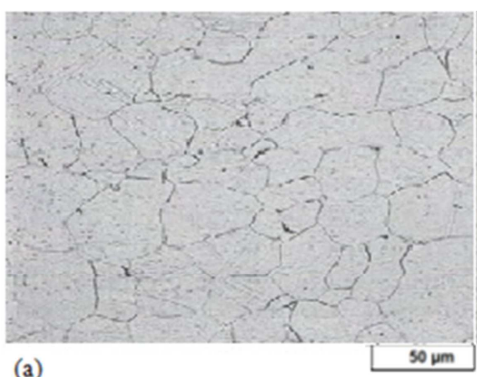

(a)

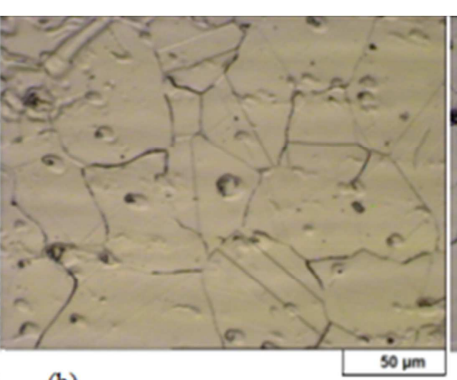

(b)

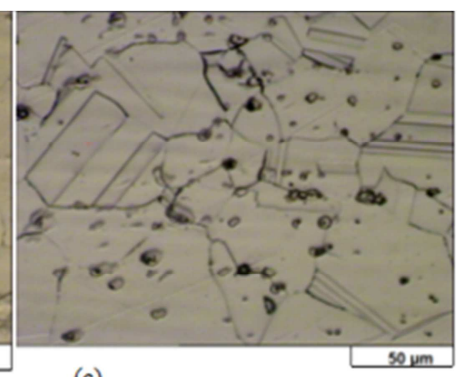

(c)

Figure 4. (a) HAZ area for one- time welding, (b) two-times welding, (c) three-times welding.

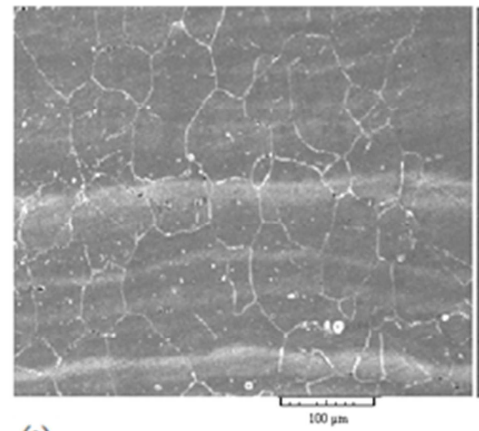

(a)

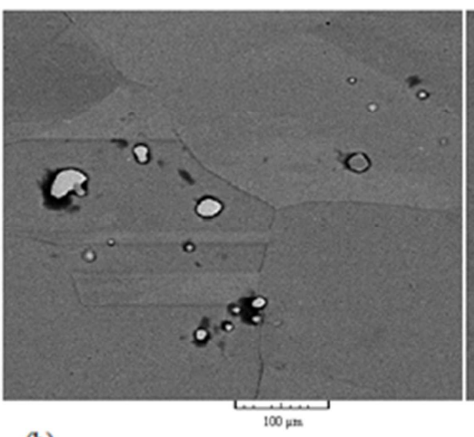

(b)

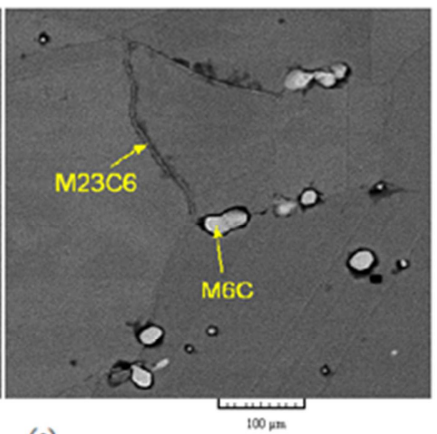

(c)

Figure 5. (a) SEM image of one-time welding, (b) two-times welding and (c) three-times welding.
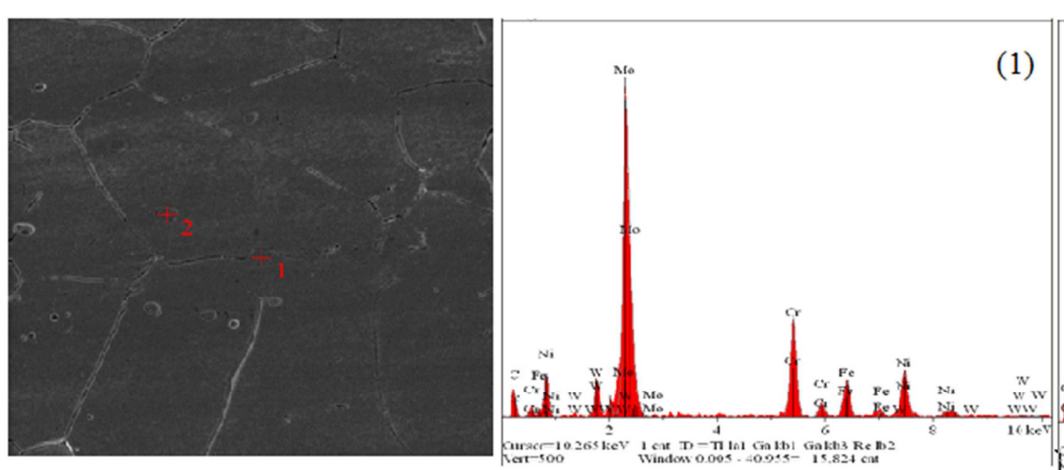

(1)

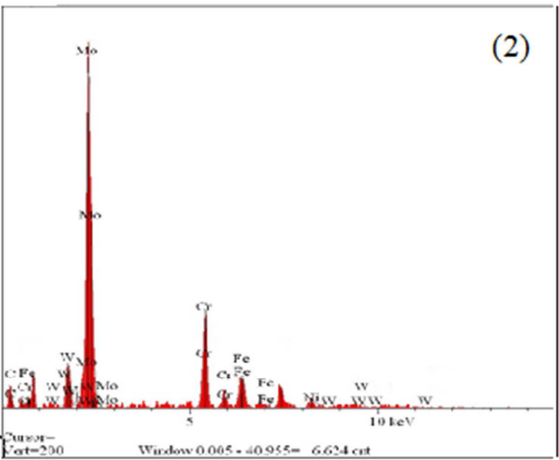

Figure 6. SEM image and EDS analysis of $M_{6}$ C carbides. $\left(\frac{M}{C}=6\right)$. 

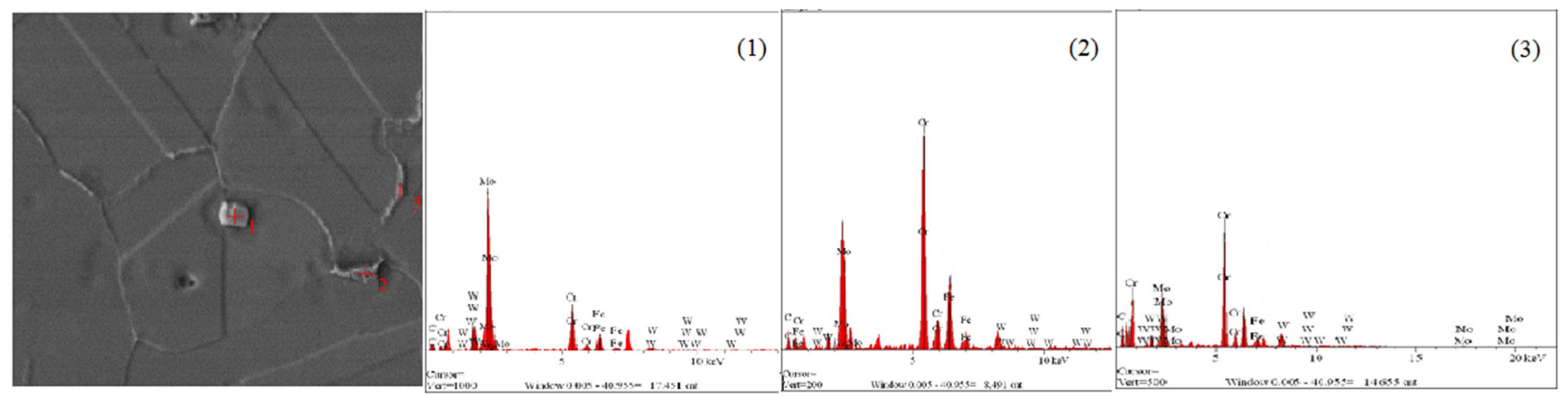

Figure 7. SEM image and EDS analysis of $M 6 C\left(\frac{M}{C}=6\right)$ and $M 23 C 6\left(\frac{M}{C}=3.83\right)$.

Table 6. Atomic table of EDS analysis for $\frac{M}{C}=6\left(M_{6} C\right)$.

\begin{tabular}{ll}
\hline Elements & Atomic \\
\hline $\mathrm{C}$ & 9.922 \\
$\mathrm{Cr}$ & 24.864 \\
$\mathrm{Fe}$ & 2.103 \\
$\mathrm{Ni}$ & 2.229 \\
$\mathrm{Mo}$ & 56.753 \\
$\mathrm{~W}$ & 4.129 \\
Total & 100.000 \\
\hline$(2)$ & \\
\hline Elements & Atomic \\
\hline $\mathrm{C}$ & 11.615 \\
$\mathrm{Cr}$ & 15.411 \\
$\mathrm{Fe}$ & 3.261 \\
$\mathrm{Ni}$ & 2.742 \\
$\mathrm{Mo}$ & 66.462 \\
$\mathrm{~W}$ & 2.510 \\
Total & 100.000 \\
\hline
\end{tabular}

Table 7. Atomic table of EDS analysis for carbides.

\begin{tabular}{llllll}
\hline Elements & Atomic & Elements & Atomic & Elements & Atomic \\
\hline $\mathrm{C}$ & 9.332 & $\mathrm{C}$ & 7.593 & $\mathrm{C}$ & 15.130 \\
$\mathrm{Cr}$ & 18.174 & $\mathrm{Cr}$ & 30.347 & $\mathrm{Cr}$ & 56.851 \\
$\mathrm{Fe}$ & 7.969 & $\mathrm{Fe}$ & 19.616 & $\mathrm{Fe}$ & 8.334 \\
$\mathrm{Mo}$ & 54.855 & $\mathrm{Mo}$ & 24.512 & $\mathrm{Mo}$ & 10.688 \\
$\mathrm{~W}$ & 9.670 & $\mathrm{~W}$ & 17.932 & $\mathrm{~W}$ & 8.997 \\
Total & 100.000 & Total & 100.000 & Total & 100.000 \\
$(1)$ & & $(2)$ & & $(3)$ & \\
\hline
\end{tabular}

Figure 3 illustrates the OM micrograph of HAZ of the samples. It can be observed that the structure of all samples was fine grained. SEM and EDS micrographs confirmed attention of two different carbides such as $\mathrm{M}_{6} \mathrm{C}$ and $\mathrm{M}_{23} \mathrm{C}_{6}$ (tables 6, 7). Also, EDS analysis showed that the mixture particles were $\mathrm{M}_{6} \mathrm{C}$ carbides enriched by molybdenum. Thus, $\mathrm{Cr}$ can be replaced with $\mathrm{M}$ in $\mathrm{M}_{23} \mathrm{C}_{6}$. The size of carbides in base metal was measured to compare the size of different carbides in HAZ zone. Average size of carbides in base metal was 6.16 and $18.71 \mu \mathrm{m}$ for $\mathrm{M}_{6} \mathrm{C}$ and $\mathrm{M}_{23} \mathrm{C}_{6}$, respectively. Comparison of Grain sizes between HAZ zone and base metal as well as weight percent of carbides played a important role on evaluation of mechanical properties [3, 4] (Fig. 5). The $\mathrm{M}_{23} \mathrm{C}_{6}$ carbides precipitated coherently in the matrix. Microstructure of HAZ zone contained fine grains (grain size number 5) GTAW method. Grain size in HAZ zone and in base metal were determined via image analysis software $[8,9]$.
Due to less grain size and carbides, hardness of the HAZ zone was higher than base metal. SEM micrographs of carbides of HAZ showed that carbides uniformly were distributed through the zone and size of carbides in HAZ was much less than that in base metal (Table 5) [10].

\subsection{Tensile Test}

Results of tensile test (DIN EN 895) performed for three specimens showed that "UTS" was approximately the same in all specimens. The strength of HAZ zone was higher than that in base metal which can be attributed to the dissolved carbides mentioned in table 5. As shown in table 8 and figure 8, increase of UTS was 1,2 , and $3 \%$, respectively, which caused fracture of base metal in all three specimens $[11,12]$.

Table 8. The results of tensile tests.

\begin{tabular}{llll}
\hline Specimen & UTS (MPa) & Average (MPa) & Y. S (MPa) \\
\hline $1-1$ & 747 & 735 & 380 \\
$1-2$ & 723 & & 395 \\
$2-1$ & 748 & 743 & 420 \\
$2-2$ & 738 & & 430 \\
$3-1$ & 749 & 753 & 410 \\
$3-2$ & 757 & & 438 \\
\hline
\end{tabular}

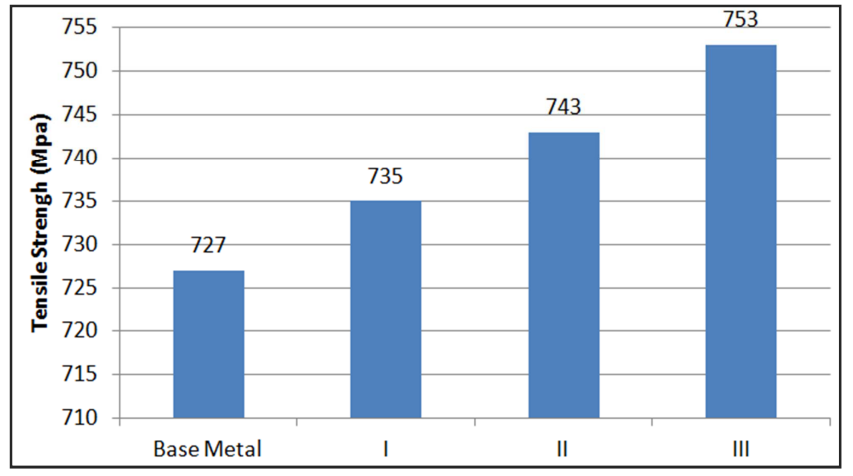

Figure 8. Tensile test of base metal and three specimens.

\section{Conclusions}

1. The hastelloy $X$ was successfully fabricated via TIG process and the effect of repair welding number on its microstructure and mechanical properties was investigated.

2. Grain size of base metal was $64.11 \mu \mathrm{m}$. Also, that of 
HAZ zone at one-time, two-time and three-time welding was $73.96,78.648$ and $81.335 \mu \mathrm{m}$, respectively. In other words, grain growth percent was 15,22 and $26 \%$, respectively.

3. The carbides observed in the base metal and HAZ zone were rich in molybdenum $\left(\mathrm{M}_{6} \mathrm{C}\right)$ and chromium $\left(\mathrm{M}_{23} \mathrm{C}_{6}\right)$ with 6.16 and $18.71 \mu \mathrm{m}$ in size, respectively which were dissolved because of the heat. Besides, reduction of carbides was 34, 49 and $50 \%$ for $\mathrm{M}_{6} \mathrm{C}$ and increasing 32 , 39 and $50 \%$ for $\mathrm{M}_{23} \mathrm{C}_{6}$, respectively).

4. As the UTS of base metal was $727 \mathrm{MPa}$ and increased 1, 2 and $3 \%$ during welding, respectively, the fracture phenomenon occurred.

5. Repair welding of hastelloy X successfully continued to three times.

\section{References}

[1] Fude Wang, Mechanical property study on rapid additive layer manufacture Hastelloy $\mathrm{X}$ alloy by selective laser melting technology, The International Journal of Advanced Manufacturing Technology, 5-8, 2012, 545-551.

[2] Jeremie Graneix, Jean Denis Beguin, Joël Alexis, Talal Masri, "Weldability of Superalloys Hastelloy X by Yb: YAG Laser", Advanced Materials Research, Vol 1099, pp. 61-70, Apr. 2015”.

[3] J. C. Lippold, J. W. Sowards, G. M. Murray, B. T. Alexandrov, A. J. Ramirez, "Weld Solidification Cracking in Solid-Solution Strengthened Ni-Base Filler Metals", 2008, pp. 147-170.

[4] J. Matthew, S. Donachie, J. Donachie, "Superalloys, A Technical Guide", 2nd ed., ASM International, USA, New York, 2002, pp. 192-265.
[5] N. S. Stoloff, "Speciality Steels and Heat- Resistant Alloy", Metals Handbook, 1ST ed., Vol. 1, ASM Handbook, 2005, pp. 1478-1549.

[6] N. L. Richards and M. C. Chaturvedi, "Effect of minor elements on weldability of Nickle base superalloys", international Materials Reviews, Vol. 45, 2000.

[7] Q. Wang, D. L. Sun, Y. Na, Y. Zhou, X. L. Han, J. Wang, "Effects of TIG Welding Parameters on Morphology and Mechanical Properties of Welded Joint of Ni-base Superalloy", Procedia engineering, 11th International Conference on the Mechanical Behavior of Materials (ICM11), 2011, 37-41.

[8] Li. Zhang, S. L. Gobbi, K. H. Richter, "Autogenous Welding of Hastelloy X to Mar-M 247 by Laser", J MaterPro Tech, 70, 1997, pp. 285-292.

[9] M. Pang, G. Yu, H. H. Wang, C. Y. Zheng, "Microstructure Study of Laser Welding Cast Nickel-Based Super Alloy K418", Journal of Materials Processing Technology, 207, 2008, pp. 271-275.

[10] R. Sihotang; P. Sung-Sang; B. Eung-Ryul, Effects of heat input on microstructure of tungsten inert gas welding used hastelloy X, Volume 18, Issue S2 (May 2014), pp. S2-1074-S2-1080.

[11] W. G. Kim, S. N. Yin, W. S. Ryu, J. H. Chang, S. J. Kim, "Tension and creep design stresses of the Hastelloy X alloy for high temperature gas cooled reactors", Materials science and engineering, 2008, p 495-497.

[12] G. D. Janaki Ram, A. Venugopal Reddy, K. Prasad Rao, G. M. Reddy, J. K. Sarin Sundar, "Microstructure and Tensile Properties of Inconel 718 Pulsed Nd-YAG Laser Welds", Journal of Materials Processing Technology, 167, 2005, pp. 73-82. 